\title{
Por uma agricultura contra-hegemônica: a função social das escolas no território camponês de Restinga Seca, RS
}

\author{
For a contra hegemonic agriculture: the social function of schools in the peasant territory of \\ Restinga Seca, RS
}

\author{
Altair Groff \\ Dourando em Geografia - Programa de Pós-Graduação em Geografia \\ Universidade Federal de Santa Maria, Brasil \\ altairgroff2@gmail.com \\ Angelita Zimmermann \\ Doutora em Geografia - Programa de Pós-Graduação em Geografia \\ Universidade Federal de Santa Maria, Brasil \\ angelitazd@gmail.com \\ Ane Carine Meurer \\ Doutora em Educação/UFBA \\ Docente do Programa de Pós-Graduação em Geografia \\ Universidade Federal de Santa Maria, Brasil \\ anemeurer@gmail.com
}

\begin{abstract}
Resumo
A produção agroecológica, o respeito à biodiversidade e o valor social da terra como bem comum a toda a humanidade, passam por uma educação contra-hegemônica. As políticas do modelo agrícola globalizado incidem nos lugares e territórios de vida camponesa e têm desterritorializado inúmeras escolas do campo e seus sujeitos no Brasil. O objetivo deste texto é socializar um estudo sobre a relação entre o agronegócio e a desterritorialização de escolas do campo no município de Restinga Seca, Rio Grande do Sul. Em uma abordagem qualitativa, a análise utilizou-se de uma pesquisa de campo, fundamentando-se em teóricos que fazem uma crítica ao agronegócio e, por consequência, aos problemas socioeconômicos e culturais vivenciados pelo campesinato. A territorialização das escolas do campo e sua função social são essenciais à emancipação dos sujeitos por meio da educação para uma agricultura contra-hegemônica, viável e sustentável. Defendemos o reconhecimento e a ampliação do território epistemológico camponês como forma de resistência e emancipação.
\end{abstract}

Palavras-chave: Restinga Seca/RS; Agricultura; Educação do Campo; Desterritorialização de Escolas do Campo.

\begin{abstract}
Agroecological production, respect for biodiversity and the social value of land as a common good for all humanity, undergo counter-hegemonic education. The policies of the globalized agricultural model affect the places and territories of peasant life and have deterritorialized countless rural schools and their subjects in Brazil. The purpose of this text is to socialize a study on the relationship between agribusiness and the deterritorialization of rural schools in the municipality of Restinga Seca, Rio Grande do Sul. In a qualitative approach, the analysis used field research, based on in theorists who criticize agribusiness and, consequently, the socioeconomic and cultural problems experienced by the peasantry. The territorialization of rural schools and their social
\end{abstract}


function is essential to the emancipation of subjects through education for a counter-hegemonic, viable and sustainable agriculture. We defend the recognition and expansion of the peasant epistemological territory as a form of resistance and emancipation.

Keyword: Restinga Seca/RS; Agriculture; Rural Education; Deterritorialization of Rural Schools.

\section{INTRODUÇÃO}

Esta reflexão busca a defesa de uma agricultura agroecológica, à produção orgânica, à pequena propriedade como espaço de diversificação de cultivos, aos diversos povos do campo, à agricultura camponesa/familiar, sistematizando experiências da aliança destes saberes/conhecimentos com o das escolas, indissociáveis à Educação do Campo. Compreendemos que, sem uma formação/escolarização condizente à realidade e aos anseios dos camponeses, não se avança em direção a uma produção distinta da utilizada pela agricultura determinada pelo capital.

Nessa temática, o objetivo do texto é socializar um estudo sobre a relação entre o agronegócio e o desterritorialização, de escolas do campo no município de Restinga Seca, Rio Grande do Sul. Em uma abordagem qualitativa, a análise utilizou-se de uma pesquisa de campo, que teve como referência o Município de Restinga Seca/RS, fundamentando-se em teóricos que fazem uma crítica ao agronegócio, às grandes propriedades e sua alta produtividade, e, por consequência, à desativação das escolas no campo e aos problemas socioeconômicos desencadeados em um campo vazio.

O município de Restinga Seca é mais uma demonstração deste panorama que ocorre em todo o Brasil, no qual extensas colinas e férteis várzeas estão cada vez mais sem moradores e o plantio parece ser cada vez mais inclinado à monocultura da soja, que se vem inserindo intensamente nestes espaços. Nele, já existiu um expressivo número de escolas para uma população em torno de 15.000 a 17.000 habitantes. Desde 1959 até os anos de 1973, contabilizaram-se 61 escolas no campo deste território.

Na relação territorialização e desterritorialização de escolas e sujeitos do campo, destacamse três planícies: a do Rio Jacuí, a do Vacacaí e a do Vacacaí Mirim. Estes rios foram fundamentais para o povoamento das comunidades, bem como para despovoá-las posteriormente. Nesta dinâmica territorial, estão envolvidas as pequenas, médias e grandes propriedades e as escolas, que, em sua maioria, encontram-se desterritorializadas. Apenas sete (7) das sessenta e uma (61) escolas já existentes no município permanecem em funcionamento, constituindo um importante território de atuação de estudantes, no sentido político, cultural e econômico.

Como contraponto, trataremos, nesta reflexão, da viabilidade reprodutiva das pequenas e médias propriedades camponesas. Compreendemos que a viabilidade da agricultura familiar alicerçada nas pequenas propriedades constitui-se em uma agricultura voltada à produção orgânica e 
ecológica, com base nos princípios da agroecologia. Nesse sentido, a justificativa enfática para a existência de Escolas do Campo se consubstancia ao fundamental papel e cumprimento da função social de serem espaços de contradição, de denúncia e de enfrentamento na luta pela emancipação dos sujeitos do campo, ainda que inseridos no agronegócio da contemporaneidade.

O agronegócio da denominada agricultura moderna dá continuidade à Revolução Verde dos anos 1960, no entanto apresenta-se muito mais abrangente, pois coloca grandes empresários, transnacionais e instituições financeiras determinando a produção de comodities e interligando camponeses e grandes empresários rurais, considerando a terra como mais uma mercadoria, sem mensurar as consequências ambientais, sociais e culturais da biodiversidade planetária.

Defendemos a ampliação do território epistemológico camponês por meio do reconhecimento do saber/conhecimento nascido das lutas vivenciadas diariamente pelos sujeitos do campo. Neste processo, a escola tem um papel fundamental de promover a criticidade necessária e as transformações concretas na (re)produção da vida, que envolvem educação, trabalho e agricultura. Por consequência, sua função social de validação e ampliação do território camponês torna-se condição primeira para sua própria territorialização.

\section{RESTINGA SECA E CONTEXTO: UM MUNICÍPIO CONSTITUÍDO DE PLANÍCIES E VÁRZEAS}

As extensões de terras no município de Restinga Seca, no Rio Grande do Sul, estão “associadas à planície, destaca-se a grande e média propriedade, e quanto ao uso da terra desenvolve-se a agricultura: nas várzeas com o cultivo de arroz e nas áreas de coxilhas o cultivo de soja e a presença de campos" (CIROLINI, 2008, p. 49). Isto é, caracterizam as terras mais requeridas pelo agronegócio e a agricultura moderna.

O município teve sua emancipação em 1961. Até então, pertencia ao município de Cachoeira do Sul e este, anteriormente, a Rio Pardo. Localiza-se na Mesorregião Centro Ocidental Rio-Grandense e integra a Quarta Colônia, com mais 08 municípios circunvizinhos.

De acordo com o Plano Municipal de Educação (PME, 2015), elaborado pela Secretaria Municipal de Educação, registra-se que, na primeira administração (1960 a 1963), a rede municipal de Ensino de Restinga Seca contava com sete (7) escolas Estaduais, cinco (5) Escolas Particulares, vinte (20) Escolas Municipais e vinte e sete (27) Escolas do Serviço de Expansão Descentralizada do Ensino Primário (SEDEP). Assim, o total de escolas em funcionamento no município era de 59, um número bastante expressivo e que abrangia quase todas as comunidades do campo e da cidade. O SEDEP foi um plano do Governador do Estado, Dr. Leonel de Moura Brizola, para dar aos municípios mais autonomia para expandir a rede de ensino. Na ocasião, criaram-se escolas em todas as comunidades para não deixar nenhuma criança sem escola. As escolas do campo, então 
denominadas escolas rurais, eram em regime de unidocência, ou seja, uma única professora que atendia simultaneamente alunos da primeira à quarta série.

Na segunda administração (1964 a 1967), a educação continuou mantendo as escolas até então constituídas. Por meio do Plano de Municipalização de Ensino, foram construídas mais quatro (4) escolas e o Grupo Escolar do Silêncio, o qual, mais tarde, passou a ser chamado de Escola Estadual de Ensino Fundamental Olmiro Pohlmann Cabral.

$\mathrm{Na}$ terceira administração (1969 a 1973), foram construídas mais nove (9) escolas no município. Podemos, dessa forma, afirmar que, em Restinga Seca, foram territorializadas aproximadamente 61 escolas no campo nos períodos de 1912 a 1973.

Entretanto, atualmente, permanecem apenas sete (7) escolas no campo, com suas atividades escolares integrando professores, alunos, merendeiras, auxiliares, estagiárias e a comunidade. Ressalta-se que as instituições que permanecem territorializadas estão assentadas num espaço de convivência de questões sociais, culturais e econômicas. Estas escolas no/do campo em atividade situam-se nas regiões em que se estabelecem o minifúndio e a média propriedade.

$\mathrm{Na}$ exposição dissertativa de Cirolini, há o demonstrativo constatado em três planícies aluviais. O mapa abaixo (Figura 01) demonstra o uso das terras em Restinga Seca, as planícies e várzeas deste município. A primeira, de maior expressão, está associada ao Rio Jacuí - leste do município, fazendo divisa com os municípios de Agudo, Paraíso do Sul e Cachoeira do Sul. Conforme a autora, reflete uma "estrutura fundiária com média de 10 a 100 hectares, sendo as propriedade menores localizadas em Vila Rosa, Várzea do Meio, Barro Vermelho e Silêncio e as maiores no Rincão das Palmas, Guardinhas e Sossego" (CIROLINI, 2008, p. 50).

Nas localidades do município em que as propriedades são menores e, consequentemente, com maior número de habitantes, está a comunidade de Vila Rosa, que tem ativada a Escola Municipal de Ensino Fundamental Sete de Setembro, e a Vila do Silêncio, onde se situa a Escola Estadual de Ensino Fundamental Olmiro Pohlmann Cabral. Estas são escolas que continuam territorializadas, contando com os docentes, discentes e comunidade responsável pelos alunos.

Já a planície aluvial do Rio Vacacaí está localizada no extremo Sul do município, com orientação oeste-leste, na parte de baixo do mapa, no limite com Formigueiro e São Sepé.

Analisando-se o tamanho das propriedade as desta planície, verifica-se que a estrutura fundiária distribui-se espacialmente em quatro grandes áreas: a primeira junto a foz dos Rios Vacacaí e Jacuí com grandes propriedades; a segunda, não contínua, apresenta médias propriedades, visto que a primeira porção localiza-se ao sul das localidades de Bom Retiro, Rincão dos Toledos, Boqueirão do Estiva e Campo Novo; a terceira porção de média propriedade encontra-se entre a Praia de Tunas e o limite Oeste do Município; por fim a última área, composta por pequenas propriedades, localiza-se junto a BR 149 e entre as duas porções constituídas por médias propriedades (CIROLINI, 2008, p. 54). 


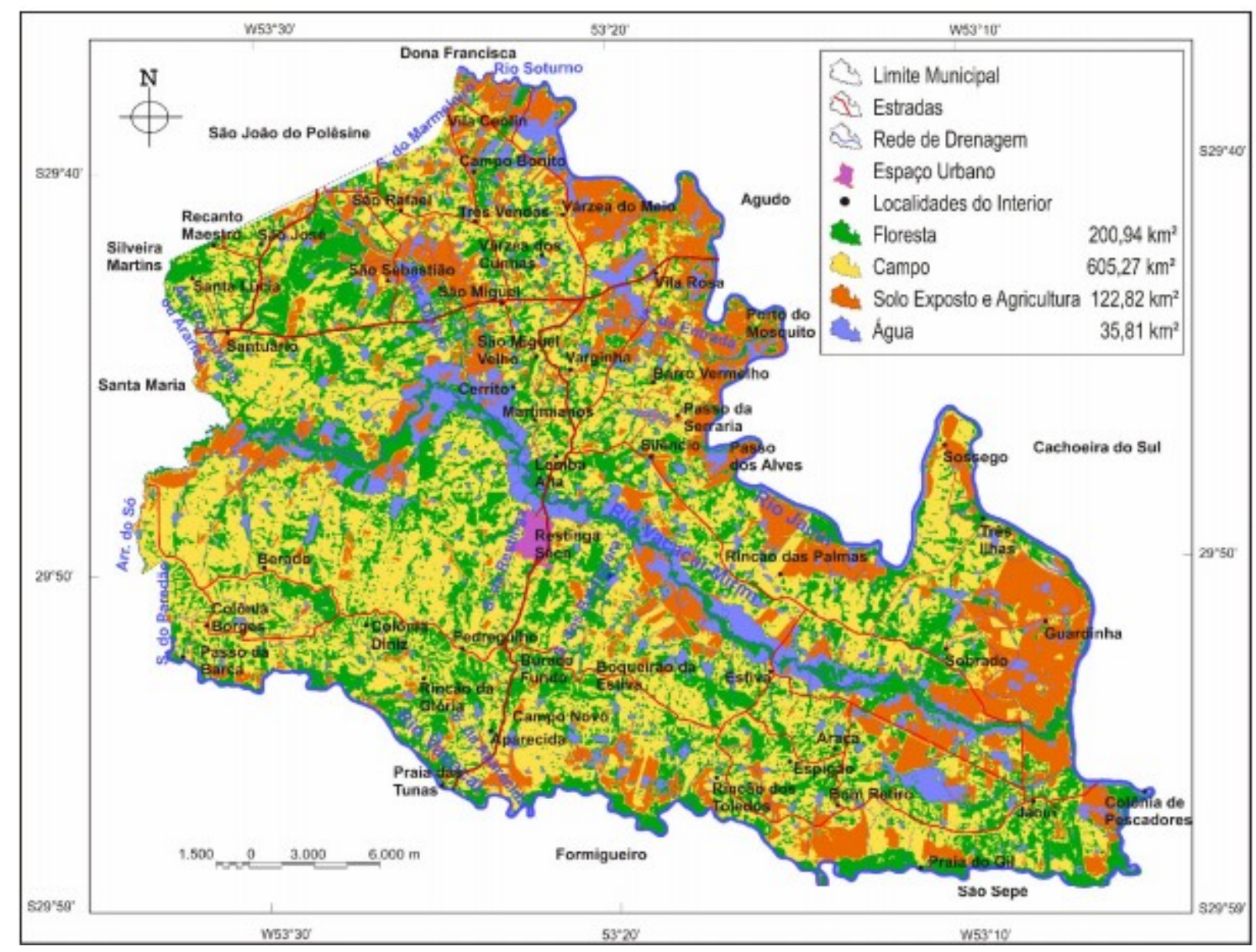

Figura 01 - Mapa de Uso da Terra no Município de Restinga Seca.

Fonte: Prefeitura Municipal de Restinga Seca.

As localidades desta planície de Restinga Seca já não têm mais as escolas, elas foram desativadas, restando as lavouras e grandes plantações de soja. E como lembrança dos "cachinhos dourados", visualizam-se as plantações de arroz que preenchem as várzeas do Vacacaí, e, quando o verde dos cachos começa a sentir o forte do sol e tornar-se de cor dourada, ao amanhecer, clama-se pelos cabelos dourados das meninas e pelo brilho dos olhos dos meninos, que agora estão distantes, longe do campo. Do mesmo modo, as escolas escondidas, sumidas não ouvem o cantar do galo, nem as bonitas palavras das professoras e dos professores que identificavam a posição geográfica do Boqueirão da Estiva em relação à viação férrea, que trazia o trem até a estação e de lá rumava para a Estação do Jacuí.

Os domicílios foram sumindo na escuridão da noite, vagando para a claridade das luminárias dos centros urbanos. Em todas essas comunidades, estabeleciam instituições de ensino municipais, que, com as crianças, deslocaram-se para um universo de ruelas e casas amontoadas; escolas no meio urbano que batalham, conclamam e persistem. Ficaram as taperas ainda presentes em poucos prédios escolares e os outros apagaram na paisagem das plantações promovidas pelo agronegócio. 
Taperas são lugares abandonados que povoam o imaginário da população do campo e testemunham um tempo em que as relações com a terra estavam impregnadas de afetividade. Rompido os vínculos entre pessoas e lugares, resta a migração para a cidade ou a extinção da família, redesenhando as paisagens desoladas da ruína (DE DAVID, 2014, p. 88).

A terceira planície aluvial é a do Rio Vacacaí-Mirim (Figura 02), que abrange a área central e sudeste do Município de Restinga Seca. "Em relação à estrutura fundiária observa-se a presença da grande propriedade na margem esquerda do Rio Vacacaí e a leste de Estiva, na margem direita, onde ocorre também a presença da pequena propriedade" (CIROLINI, 2008, p.55). A autora acrescenta que, nestas unidades, em termos de uso da terra, há áreas de campos limpos de 85\% a $90 \%$ da área total do município e áreas menores são ocupados por capões de mato e matas, galerias ao longo dos rios, riachos, sangas e banhados.

Entre as planícies dos rios Jacuí e Vacacaí-Mirim, quanto à distribuição espacial das localidades nestes dois alinhamentos de coxilhas, no que está ao norte da cidade, no sentido noroeste-sudeste, encontram-se as localidades de São Rafael, Três Vendas, Várzeas dos Cunhas, São Miguel, São Miguel Velho, Martimianos, Lomba Alta, rincão das Palmas e Sobrado.

Nessas comunidades, estão ativadas a Escola Municipal de Ensino Fundamental Três de Outubro, na comunidade de Lomba Alta; a Escola Municipal de Ensino Fundamental Albino Carvalho, na comunidade de São Miguel Velho; e a Escola Municipal de Ensino Fundamental Desidério Fuzer, na comunidade de São Miguel. A presença da pequena propriedade de abrangência das três escolas é saliente, uma vez que o êxodo rural nestas comunidades não foi tão acentuado quanto nas demais.

No alinhamento, no sentido oeste-leste, onde se encontra e sede municipal, tem-se as localidades de Colônia Borges, Beirado, Colônia Diniz, Rincão da Glória, Pedregulho, Boqueirão da Estiva, Espigão, Bom Jesus e Jacuí. "Estas comunidades situadas sobre esta planície têm como cultura principal a lavoura de arroz" (CIROLINI, 2008, p. 60). No entanto, nos últimos anos, a cultura da soja tem se homogeneizado de forma bastante intensa.

Neste alinhamento, em que há o limite de Restinga Seca e Colônia Borges com Santa Maria, está o Distrito de Arroio do Só, onde se sobressai a produção de porongos em pequenas propriedades, sob o trabalho do sistema da agricultura familiar (CANCELLER, 2018, p. 27). Na comunidade de Colônia Borges, está em atividade a Escola Municipal de Educação Fundamental Adelino Roso. As outras escolas no campo que ocuparam as comunidades desta planície estão hoje apenas nos registros da Secretaria Municipal de Educação. 


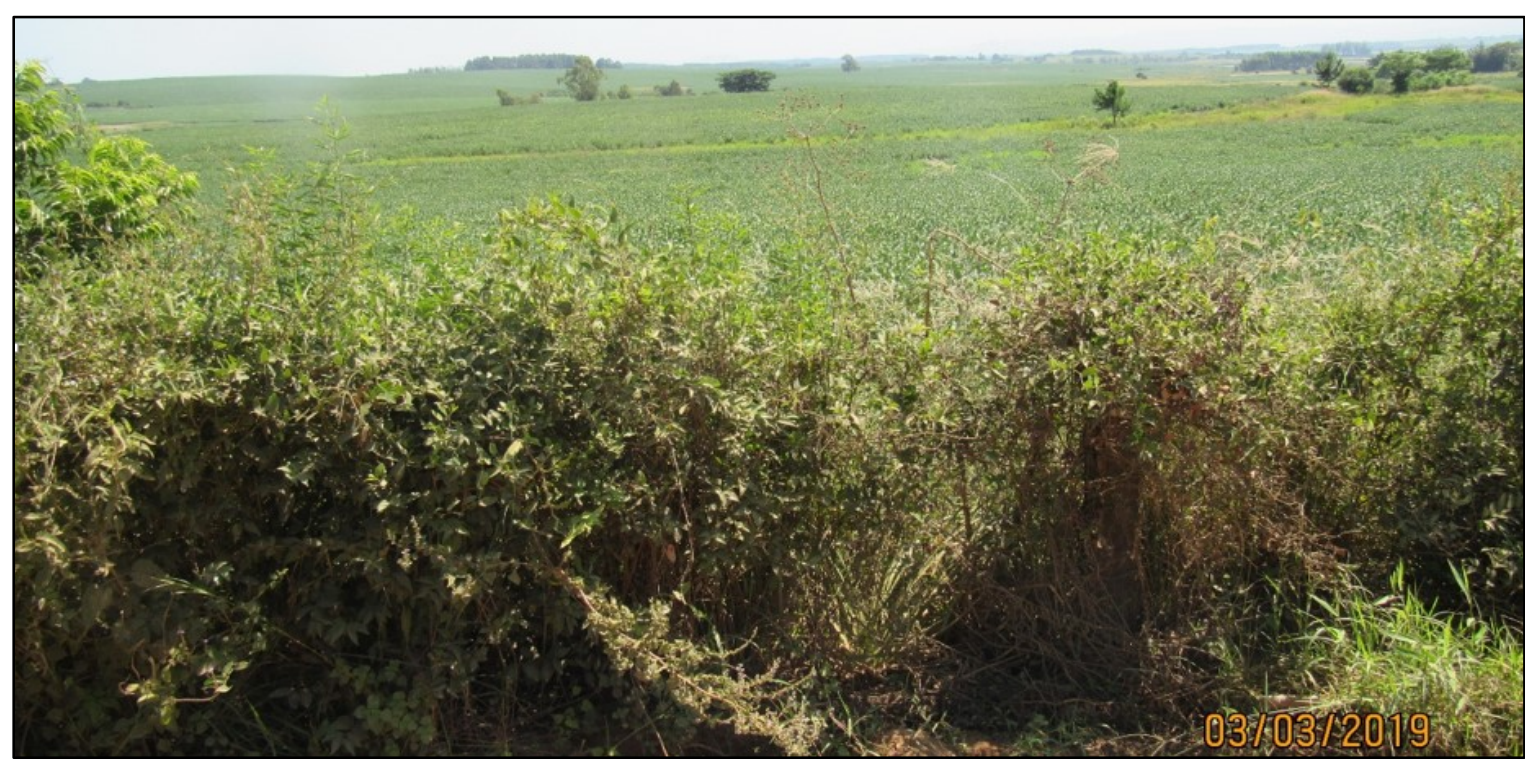

Figura 02 - Lavoura de soja na Comunidade Boqueirão da Estiva.

Fonte: Acervo dos autores, 2019.

Muitos dos prédios destas escolas já tiveram o seu desmanche (Figura 03) e, talvez, nem sequer uma fotografia sobrou para conseguir revelar os escritos em que o giz e as crianças interagiam, soletrando e aprendendo o alfabeto que compõe todas as palavras dos idiomas que impulsionam o aprendizado e a libertação no sentido de Paulo Freire na Pedagogia do Oprimido.

A pequena propriedade no Município de Restinga Seca está situada com mais continuidade no rebordo do planalto, ou seja, em uma pequena área localizada nos limites com o município de Santa Maria e São João do Polêsini. Nela, estão as localidades de Santa Lúcia e parte do Recanto Maestro. As escolas construídas nestas comunidades atendiam as crianças do local, que tinham famílias que viviam da diversidade da produção e criação em suas propriedades/moradias.

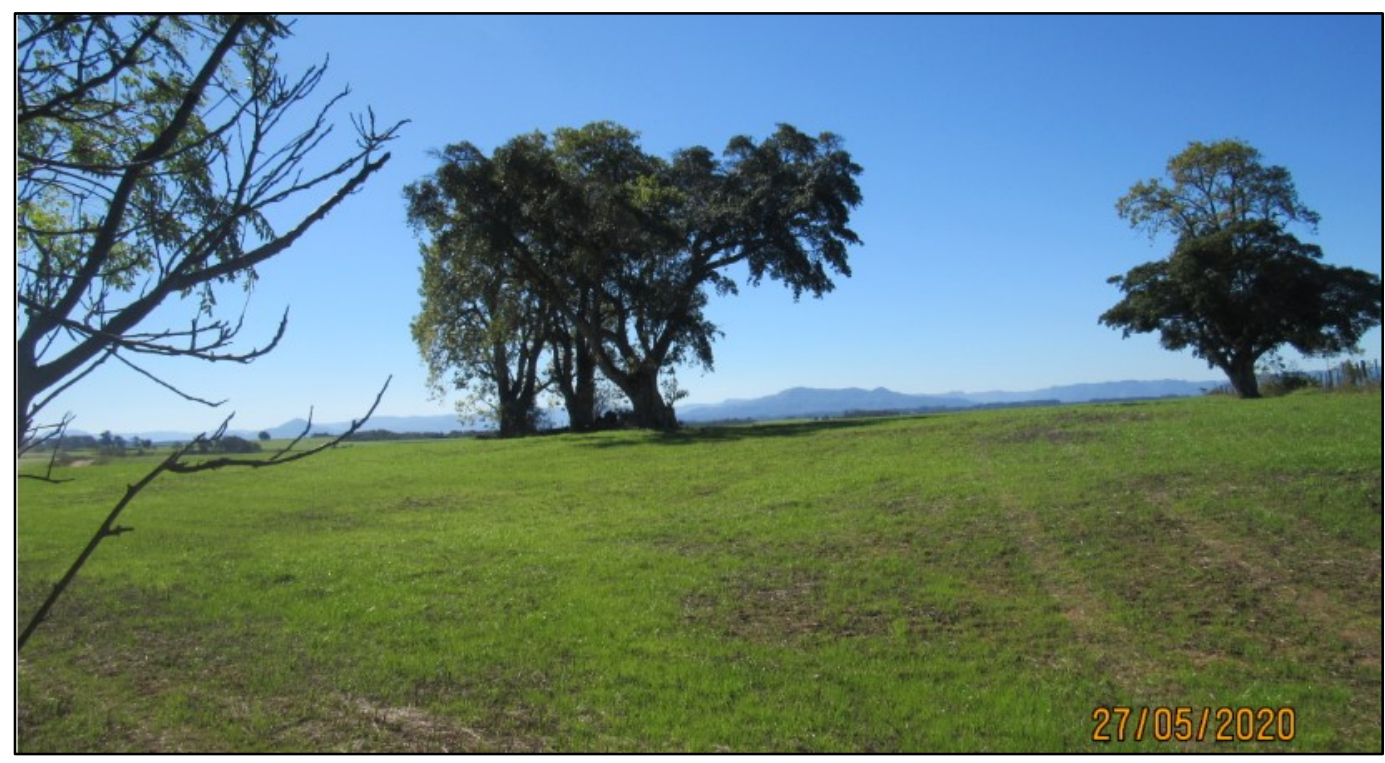

Figura 03 - Aqui estava a Escola Dom Pedro I - Rincão da Palma.

Fonte: acervo dos autores, 2020. 
Contudo, todas as escolas amargaram as despedidas de seus estudantes e o eco das vozes das crianças que sumiram no topo das árvores rumando ao infinito. Com a migração desta população para as cidades, permanecem, atualmente, as pessoas idosas e alguns proprietários que compraram as terras dos vizinhos. As escolas foram, em pouco tempo, sumindo por entre o nevoeiro das montanhas que circundam as comunidades. Tornaram-se taperas que continuam amanhecendo no aguardo daquela população que está além dos montes, na cidade, dividindo salas de aulas entre 25 a 30 estudantes.

\section{O AGRONEGÓCIO E AS ESCOLAS DO/NO CAMPO}

Especialmente a partir dos anos 1990, a denominada modernização da agricultura, iniciada pela Revolução Verde ${ }^{1}$ que se insere nas atividades agropecuárias e com ênfase no Brasil e América Latina, a partir dos anos 1960, integra uma política de produzir grandes quantidades de comoodities, com um mínimo de mão de obra, deixando os campos sem gente e as cidades cada vez mais populosas. "A consolidação efetiva da agricultura moderna ocorreu a partir de 1960, com a adoção das inovações tecnológicas no processo produtivo (inovações agronômicas, físico-químicas, biológicas).” (MATOS; PESSOA, 2011, p. 2). Já o termo agronegócio vem sendo incorporado no sistema da produção agrícola em vários países a partir da década de 1980, sendo que alguns pesquisadores passaram a incorporá-lo no vocabulário para denominar "racionalidade no processo produtivo capitalista no campo" (MATOS; PESSOA, 2011, p.4).

As transformações sociais, econômicas e territoriais do século XX e XXI, determinam e globalizam uma política de ampliação do capital. Assim, o modo de produção capitalista neste momento histórico preconiza o crescimento econômico e financeiro dos burgueses nacionais com alianças internacionais (OLIVEIRA, 2016). A mundialização do agronegócio baseado na inserção de insumos e tecnologias e, consequentemente, na concentração de terras para poucos proprietários, que passam a ser denominados empresários rurais, elege como negócio principal a ocupação do máximo de terras, para sua expansão por meio de mercadorias para a exportação.

No município de Restinga Seca e Região Central, a produção da soja teve seu plantio bem mais tarde, após as décadas de 1990. O cultivo do arroz e a criação do gado eram dominantes antes disso. Mas a imersão foi sendo efetivada, uma vez que os campos pertenciam a poucos proprietários e foram sendo transformados em lavouras. Os próprios vizinhos com pequenas propriedades, e

\footnotetext{
1 A expressão Revolução Verde refere-se à invenção e disseminação de novas sementes e práticas agrícolas que permitiram um vasto aumento na produção agrícola a partir da década de 1960 nos Estados Unidos e na Europa e, nas décadas seguintes, em outros países. ${ }^{[1]} \mathrm{E}$ um amplo programa idealizado para aumentar a produção agrícola no mundo por meio do uso intensivo de insumos industriais, mecanização e redução do uso de mão de obra. O modelo se baseia na intensiva utilização de sementes geneticamente alteradas (particularmente sementes híbridas), insumos industriais (fertilizantes e agrotóxicos), mecanização, produção em massa de produtos homogêneos e diminuição do uso de mão de obra.
} 
mesmo os que tinham médias ou grandes, foram sendo isolados e persuadidos a venderem suas áreas de terras, por diversas razões, entre elas, dívidas adquiridas com financiamentos.

As escolas que abrigavam em suas manhãs e tardes os filhos destes camponeses viram as crianças migrando para outras escolas, centradas nas periferias, nas vilas, nos bairros dos meios urbanos.

\begin{abstract}
Além dos graves impactos causados ao meio natural, devido ao uso intenso e impróprio de técnicas e de produtos químicos, a modernização da agricultura foi responsável pelo aumento da desigualdade. No campo, a concentração fundiária tornou-se maior, o êxodo rural aumentou e os meios de produção modernos tornaram-se quase que inacessíveis aos pequenos produtores. Desse modo, a concentração da propriedade fundiária resultou no esvaziamento do campo (DE DAVID, 2014).
\end{abstract}

Em Restinga Seca, as terras de planícies, tanto as do Rio Jacuí quanto as do Vacacaí, estão situadas em grandes propriedades, onde permanece a monocultura, especialmente a da soja. Até o gado solto pelo campo vem sendo encurralado em regime de confinamento. Os campos foram secando e a grama e a monocultura passaram a validar a Revolução Verde e, atualmente, o agronegócio.

Neste contexto, o agronegócio, impulsionado pelos governos, grandes indústrias, empresários e proprietários, passou a utilizar-se das terras planas, várzeas, coxilhas para o plantio da soja, uma vez que esta comodities se introduziu no mercado, especialmente nos países asiáticos, como na China, país de maior destino da exportação do complexo da soja do Rio Grande do Sul no ano de 2015, ou seja, 88\% da produção brasileira (FEE, 2016).

Com a política agrícola global e da América Latina voltada a uma agricultura moderna, empreendedora e especulativa, com um máximo de lucro, a terra perde sua função social, que é a produção de alimentos para o consumo local com vistas à Soberania Alimentar. Nesse processo, passou um período muito rápido na linha do tempo, comparado aos demais períodos históricos até 2020. Matos e Pessoa (2011, p. 8) contabilizam o tempo cronológico em frações minúsculas comparado ao histórico temporal sobre a agricultura. "Em poucos mais de dez anos de investimentos do governo para modernizar o campo brasileiro, os resultados começaram a aparecer, sobretudo, a produção de commodities, como a soja”. Este grão tomou espaço de diversas culturas tradicionais em razão da demanda internacional.

Mas esta modernização deixou de fora a maioria dos produtores responsáveis pela produção, ainda hoje, dos alimentos consumidos pela população latino-americana e pelo mundo todo. O custo da implantação de um sistema concentrador, excludente dos habitantes dos territórios camponeses, indígenas, quilombolas, povos da agricultura familiar/camponesa, e a consolidação da agricultura moderna causaram graves danos sociais e ambientais, tais como: uso intenso de agrotóxicos, sementes modificadas geneticamente, perda dos modos de vida e da cultura 
camponesa, fim das nascentes de água, extinção de animais e da biodiversidade ambiental, desequilíbrio climático, pobreza, doenças e falta de bem-estar social.

Como consequência do agronegócio e da modernização da agricultura, deu-se a desativação, ou mais especificamente, a desterritorialização das escolas no/do campo em número bastante acentuado e preocupante (GROFF; MEURER, 2018).

Souza et al. (2016) afirmam que o agronegócio é a causa principal do fechamento de escolas no estado de Goiás. Podemos afirmar que isso ocorre também em outras partes do país, em específico na Região Sul, referendando o Município de Restinga Seca.

\footnotetext{
O território do camponês na sua materialidade, imaterialidade é tido como atrasado, alimentando a ideia de campo como espaço do arcaico e desnecessário à nova ordem imposta no campo. Esse paradigma que vem se materializando por meio do agronegócio no Estado de Goiás, corrobora decisivamente para o fechamento das escolas no campo, pois ele orienta políticas públicas no campo que negam o direito à constituição da vida do camponês. (SOUZA et al., 2016, p. 5)
}

Groff e Meurer (2018) demonstram em sua pesquisa que o número de escolas desativadas no Município de Dona Francisca, próximo ao de Restinga Seca, municípios interligados pelo Rio Jacuí. Em Dona Francisca, das nove (9) escolas municipais no campo, oito (8) foram desativadas após o ano de 1990, um processo que já vinha sendo construído desde 1960.

Desse modo, compreendemos que o agronegócio e a desterritorialização de escolas do campo estão inteiramente associados. Para Fernandes (2012), o agronegócio é o novo nome dado ao modelo de desenvolvimento econômico da agropecuária capitalista e, com ele, a expropriação do território camponês.

\section{AGRICULTURA CAMPONESA/FAMILIAR: VIABILIDADE DAS PEQUENAS E MÉDIAS PROPRIEDADES}

Na América Latina, como no Brasil, a produção de alimentos que vão para a mesa está constituída, em sua essencialidade, nas pequenas e médias propriedades. Mesmo sendo um dos maiores concentradores de terras, em que poucos detêm uma quantidade exorbitante de terras, em nosso país, é a pequena e média propriedade que produzem a maior parte dos alimentos para a população, ou seja, 70\% da produção (BRASIL, 2019).

Restinga Seca, em 2015, contava com 15.849 habitantes, sendo 8.982 residentes no meio urbano e 6.868 no campo. A estimativa para este ano, 2020, é de 15.789. Segundo dados do IBGE (Censo Agropecuário, 2006), o número de estabelecimentos da agricultura familiar era de 1.680, e o pessoal ocupado na agricultura familiar em Restinga Seca era de 4.551. Somente os cadastrados no Pronaf (Programa Nacional de Auxílio Financeiro) somavam mais de 70\% dos 6.868 residentes no meio rural. 
Estas famílias estão situadas nas pequenas propriedades localizadas basicamente onde houve a colonização alemã, italiana, quilombola, de descendentes afros, que continuam produzindo alimentos básicos ao consumo necessário à população. Uma porcentagem destes alimentos é fornecida às escolas, segundo a Prefeitura Municipal (2016).

A Cooperativa da Agricultura Familiar de Restinga Seca (COOPAGRES) ressalta que o município compra tomate, repolho, peito de frango, pão sovado, pão francês, mel, leite, laranja, couve, cenoura, cebola, bolacha, beterraba, iogurte, batata, banana, alho, alface e abóbora. Desse modo, a agricultura familiar promove uma importante transformação na alimentação escolar, ao permitir que alimentos saudáveis e com vínculo regional possam ser consumidos diariamente pelos alunos da rede pública municipal. Segundo a nutricionista, além dos benefícios para os educandos, a inserção da agricultura familiar no Programa Nacional de Alimentação Escolar (PNAE) beneficia também os agricultores pela geração de renda e a manutenção deles no meio rural (Prefeitura Municipal, 2016).

\section{RESISTÊNCIA E AMPLIAÇÃO DO TERRITÓRIO EPISTEMOLÓGICO CAMPONÊS: UMA LUTA CONTÍNUA}

Como vimos, nas últimas décadas, escolas foram sendo desativadas na região dos municípios de Restinga Seca e Dona Francisca, no Rio Grande do Sul (GROFF; MEURER, 2018), um processo iniciado desde a implantação da agricultura moderna que retirou e continua expropriando camponeses, via política do agronegócio no mundo todo.

Dialeticamente, ocorrem lutas por educação, produção de bons alimentos, saúde, proteção e cuidado com a biodiversidade e as diversas culturas que formam o território camponês. São movimentos sociais de resistência diária, organizados em cooperativas, coletivos diversos, universidades, instituições e pessoas que se interessam e juntam-se pelo mesmo objetivo, a busca por uma agricultura agroecológica e para todos.

Contudo, a ciência eurocêntrica se tornou, historicamente, o único conhecimento entendido como científico pelo capital, destituindo as diversas dinâmicas de saberes e fazeres que produzem um conhecimento concebido como ancestral, artesanal, tradicional entre os povos do campo e o território e que são possíveis somente na agricultura camponesa, na agricultura composta pelo modo de vida, pelo trabalho familiar, na pequena propriedade e pelos sujeitos do campo. São estas experiências que formam o campesinato e seu território.

Portanto, faz-se urgente e necessário darmos visibilidade às reflexões nascidas dos processos de produção do conhecimento em atividades coletivas e de diferentes tipos, na relação entre conhecimento e experiência e em sua validação, cuja designação torna-se um conjunto de estratégias utilizadas para resolver problemas da vida cotidiana dos camponeses. É importante o 
reconhecimento do modo de vida, da cultura, da luta e resistência de camponeses, quilombolas, indígenas, ribeirinhos, meeiros, atingidos por barragens, trabalhadores do campo, sujeitos que precisam trabalhar no campo e na cidade para complementar renda, enfim toda a forma de enfrentamento da classe trabalhadora frente às imposições globais de ampliação do capital pelo agronegócio.

A luta precisa mostrar variadas possibilidades de conhecer e de fazer ciência, ou seja, desconstruir a ideia de que a ciência deva dominar a natureza e produzir uma ciência que compreenda o cuidar da natureza. Defendemos a produção deste espaço como o território espistemológico camponês, que vem sendo produzido pelas relações interculturais entre os movimentos sociais do campo (MST, Via Campesina, etc.), escolas do campo, universidades (cursos superiores em educação do campo), instituições e comunidades, casas familiares rurais, escolas familiares agrícolas e o espaço de vida dos egressos, conhecimentos que possam ser validados pela estrutura, pela origem, pelo método e pela possibilidade de transformação do próprio conhecimento (formalização que liga experiência e conhecimento científico) e da vida dos envolvidos (ZIMMERMANN, 2019).

As escolas do campo são essenciais nesse processo e somente continuarão territorializadas se cumprirem sua função social, que é a emancipação dos sujeitos por meio da educação por uma agricultura contra-hegemônica, viável e sustentável, constituída em pequenas propriedades. Reconhecer o conhecimento camponês, validá-lo em seus Projetos Político-Pedagógicos e, em decorrência, produzir as transformações na vida concreta dos seus estudantes, egressos, famílias e comunidades de atuação, deve ser o objetivo principal destas instituições.

\section{CONSIDERAÇÕES FINAIS}

A intrínseca relação entre Educação do Campo e uma agricultura agroecológica e viável passa pela ampliação e fortalecimento do território camponês. Ao socializarmos este estudo sobre a relação entre o agronegócio e a desterritorialização, de escolas do campo no Município de Restinga Seca, Rio Grande do Sul, queremos chamar a atenção aos problemas sociais causados pela política agrícola mundial viabilizada pelo agronegócio.

Defendemos uma agricultura agroecológica, a terra como bem comum e a cultura, o modo de vida camponês como continuidade possível do planeta. Neste processo, juntamos esforços em prol da territorialização das escolas do campo, exaltando o conhecimento da experiência de vida camponesa e dos sujeitos que valorizam a vida e a biodiversidade da natureza como um todo.

A luta pela permanência do campesinato não é somente por eles, mas é por todos nós brasileiros, que, cada vez mais, teremos dificuldade em atingir uma alimentação e nutrição básica. 
São formas de cultivo, experiências, saberes historicamente construídos por esses camponeses que se perdem quando inviabilizamos a sua existência nas pequenas propriedades. A diversidade e a pluralidade (cultural, alimentar, tradicional, etc.) do campo é revertida em diversidades, tanto no campo quanto na cidade, pois se inter-relacionam, se interconectam.

Agricultura camponesa e agricultura capitalista (FERNANDES, 2012) são projetos de sociedade opostos e paradoxais. As escolas do campo são espaço-tempo de reconhecimento, debate e articulação desses projetos, para que as gerações vindouras estejam esclarecidas sobre a importância que têm, para a preservação do que ainda temos de diversidade nutricional em nosso país.

\section{REFERÊNCIAS}

BRASIL. Balança Comercial do Agronegócio - Junho/2019. Brasília: Ministério da agricultura, pecuária e abastecimento, 2019. Disponível em: $<$ http://www.agricultura.gov.br/noticias/vendasexternas-do-agro-em-junho-somam-us-8-34-bi/Notaimprensajunhode2019.docx $>$. Acesso em: 20 ago. 2019.

CIROLINI, A. Atlas eletrônico e socioeconômico sob a perspectiva da cartografía escolar no Município de Restinga Seca/RS. 2008. 281 f. Dissertação (Mestrado em Geografia) - Centro de Ciências Naturais e Exatas, Universidade Federal de Santa Maria, Santa Maria, 2008.

DE DAVI, C. "O campo se fez tapera...": as paisagens do abandono no espaço rural sul-riograndense. In: PIMENTA, M. C. A.; FIGUEIREDO, L. C. Lugares: patrimônio, memória e paisagens. Florianópolis: Editora da UFSC, 2014.

FERNANDES, Bernardo M. Território Camponês. In: CALDART, R. S.; PEREIRA, I. B.; ALENTEJANO, P.; FRIGOTTO, G. (Orgs.). Dicionário da Educação do Campo. Rio de Janeiro; São Paulo: Expressão Popular, 2012. p. 744-748.

GROFF, A.; MEURER, A. C. A desterritorialização das escolas no campo do Município de Dona Francisca/RS. São Leopoldo. OIkos, 2018. Disponível em: http://oikoseditora.com.br/files/ A\%20desterritorializa \%C3\%A7\%C3\%A3o\%20das\%20escolas\%20no\%20campo\%20-\%20Ebook.pdf $>$. Acesso em: 06 jun. 2020.

OliVEIRA, A. U. A Mundialização da Agricultura Brasileira. São Paulo: Iandé Editorial, 2016. Disponível em: http://agraria.fflch.usp.br/sites/agraria.fflch.usp.br/files/LIVRO.pdf. Acesso em: 12 mai. 2020.

MATOS, P. F.; PESSOA, V. L. S. A modernização da agricultura no brasil e os novos usos do território. Geo UERJ, Rio de Janeiro, v. 2, n. 22, p. 290-322, 2011.

PREFEITURA MUNICIPAL DE RESTINGA SECA, 2016. Disponível em: http://www.restinga seca.rs.gov.br/midias/noticias/70da-merenda-escolar-vem-da-agricultura-familiar/247 Acesso em: 06 jun. 2020. 
PME. Plano Municipal de Educação, 2015 a 2025. SME, Restinga Seca, 2015. Disponível em: http://www.ufrgs.br/monitoramentopne/planos-municipais-de-educacao-rs/r/restinga-seca, acesso em: 16 mar. 2020

SOUZA, F. E.; BIBIANO, G. L.; ABE, T. A. J.; ROCHA, D. L.; SANTOS, C. B. R. Panorama do fechamento de escolas no campo do Estado de Goiás de 2007 a 2015. Boletim DATALUTA, $n$. 105, p. 1-9, 2016.

SOUZA, F. E. As "geografias" das escolas no campo do município de Goiás: instrumento para a valorização do território do camponês?. Tese (Doutorado em Geografia) - Faculdade de Ciências e Tecnologia, Universidade Estadual Paulista, Presidente Prudente, 2012.

TOLEDO, V. M. Agroecología, sustentabilidad y reforma agraria: la superioridad de la pequeña producción familiar. Agroecologia e Desenvolvimento Rural Sustentável, Porto Alegre, v.3, n.2, p. 27-37, 2002.

ZIMMERMANN, A. "A gente tem muito pra contar!” O território epistemológico camponês por egressos de casas familiares rurais do Brasil e de Portugal. 2019. 385 f. Tese (Doutorado em Geografia) - Universidade Federal de Santa Maria, Santa Maria, 2019. 